\title{
Canada, Neurosurgery, and 5-Aminolevulinic Acid (5-ALA): The Long and Winding Road
}

Keywords: GLIOMA, resection, 5-ALA

The approval of an 'agent' that might be useful in the management of a disease is never easy. Conceptually, an 'agent' might be a drug or a device. Interestingly in many jurisdictions, it is easier to get approval for a device than it is for a drug. However, when the 'agent' might be considered a drug and/or a device, the approval process can be especially difficult and frustrating. Such has been the case in Canada with the approval of the optical imaging 'agent' 5-aminolevulinic acid (5-ALA), given orally as an adjunct for the visualisation of malignant tissue during the neurosurgical removal of brain tumours. Indeed, here in Canada, it has been a long and winding road with a still uncertain future.

In neuro-oncology, it is now generally accepted that, compared with subtotal resection, gross total resection of a malignant high-grade glioma (such as glioblastoma) substantially improves overall survival and progression-free survival (even though the quality of the supporting evidence is moderate to low). ${ }^{1}$ If one accepts this premise (and most neuro-oncologists and neurosurgeons do), then it would only seem logical that any adjunct to help maximise the surgical resection of a high-grade glioma would be accepted with open arms and gain quick approval. Yet this is where the difference between a device and a drug can prove to be problematic.

Neurosurgical devices to optimise brain tumour localization and resection have been around for decades. ${ }^{2}$ They have been developed globally, including right here in Canada. Such devices include stereotactic frames that are fixated to a patient's head prior to surgery, optically based neuronavigation machines and intraoperative modalities such as intraoperative ultrasound and intraoperative magnetic resonance imaging (iMRI). Often with industry support for development, these devices have been generally incorporated into neurosurgical practice with little fanfare (and even less clinical trial requirement!) for not only brain tumour surgery but also for many neurosurgical procedures. However, when studies are done to look at the usefulness of these devices (mostly retrospectively!), the results can be variable. Recently, a study done by our group showed increased accuracy and decreased complications using an image-guided approach compared with a traditional approach for Ommaya reservoir insertion. ${ }^{3}$ Yet an earlier study, looking at the use of imageguidance in ventricular cerebrospinal fluid shunt catheter placement, did not show a clear benefit when using image-guidance technology. ${ }^{4}$ The bottom line however remains: most neurosurgeons routinely incorporate the use of image-guidance into their surgical procedures, especially brain tumour surgery, without thinking twice (and have done so for over 20 years).
5-Aminolevulinic acid (5-ALA) has also been around for a couple of decades. The 'development' of this oral agent (drug?) is based on the capacity of malignant tissue to preferentially synthesise or accumulate fluorescent and photosensitizing endogenous porphyrins after excess administration of 5-ALA, a naturally occurring precursor in the heme biosynthesis pathway. ${ }^{5}$ When applied to malignant high-grade gliomas, the porphyrin accumulation would allow fluorescence detection within the brain - but it would be restricted to malignant cells. So ... give the patient oral 5-ALA ... resect the bulk of the tumour that is easily seen with white light ... shine fluorescent light on the brain ... visualise residual malignant brain tumour cells around the tumour cavity ... remove the residual cells - maximal extent of resection! Neurosurgeons rejoice. Not so fast.

The use of 5-ALA in brain tumour surgery started in Europe. Walter Stummer and his group in Germany published papers at the end of the last century and into the early part this century showing the feasibility and effectiveness of the technique. 5,6 This early work was followed by the 2006 5-ALA multicentre, randomised phase III study (led by Stummer) showing that neurosurgeons using 5-ALA fluorescence-guided surgery as a surgical adjunct could achieve more complete resections of tumours in high-grade glioma patients and achieve better patient outcomes than with conventional microsurgery. ${ }^{7}$ The results of this study led to the approval of 5-ALA by the European Medicine's Agency (EMA) in 2007. ${ }^{8}$ Neurosurgeons rejoice! Again, not so fast.

More publications from Europe and other parts of the world followed over the next decade looking at the use of 5-ALA. Among other things, these studies adjusted for bias, ${ }^{9}$ looked at combining the use of 5-ALA with $\mathrm{iMRI}^{10}$ and even included a systematic review and meta-analysis of prospective studies. ${ }^{11}$ Yet despite continued scientific endorsement, the use of 5-ALA could not gain approval in the United States and Canada. Why so? Apparently much of the delay came down the U.S. Food and Drug Administration (FDA) and how it conceptualised 5-ALA as a therapeutic drug rather than as an intraoperative imaging adjunct to be used with a device (a fluorescent microscope in the operating room) - the drug versus device dilemma. This led to a series of FDA requirements (the details which are painstakingly outlined in reference ${ }^{8}$ ) that eventually led to FDA approval of 5-ALA in June of 2017 in the United States (some 10 years after its approval in Europe!). Canadian neurosurgeons rejoice! Again, not so fast.

Received May 15, 2020. Date of Acceptance May 18, 2020. 
Often approval of an 'agent' (drug or device) by the FDA in the United States leads to approval of the same 'agent' by Health Canada - often ... but not always. Approval for the use of 5-ALA in Canada has yet to occur and the reasons are not entirely clear, though cost may be a significant factor. To complement recent publications that continue to provide scientific support for the use of 5-ALA in high-grade glioma surgery, ${ }^{12,13}$ Canadian neurosurgeons and researchers have now turned to economic analyses to bolster the justification for the use of 5-ALA. The paper entitled 'The cost-effectiveness of 5-ALA in high grade glioma surgery: a quality-based systematic review' in this edition of the Canadian Journal of Neurological Sciences endeavours to do just that. ${ }^{14}$ Although studies that look at the economics of health care can be challenging and fraught with inaccuracies and bias, this paper shows that there might be a health economic benefit of using 5-ALA as an intraoperative adjunct for high-grade glioma resection. It serves to supplement an even more detailed analysis done recently in Ontario as part of the Ontario Health Technology Assessment Series ${ }^{15}$ (92 pages!). In that paper, the authors found that '5-ALA-guided surgical resection of high-grade gliomas may improve 6-month progression-free survival, and may improve overall survival'. ${ }^{15}$ Moreover, the authors state: 'We estimate that publicly funding 5-ALA-guided surgical resection in Ontario over the next 5 years would result in a budget impact of about $\$ 930,000$ in year 1 to about $\$ 1,765,000$ in year 5 , yielding a total 5-year budget impact of about $\$ 7,550,000^{15}$ - which may not be so great an amount for what seems to many neurosurgeons as an 'obviously' useful 'agent', even in these covid-challenged times. So, Canadian neurosurgeons rejoice? (after 20 plus years!!). Maybe.

\section{Disclosures}

The author has no conflicts of interest to declare.

Joseph F. Megyesi, MD, PhD, FRCSC, Division of Neurosurgery, Department of Clinical Neurological Sciences, Western University, LHSC-University Hospital, London, Ontario, Canada

Correspondence to: Joseph F. Megyesi, MD, PhD, FRCSC, Professor, Division of Neurosurgery, Department of Clinical Neurological Sciences, Western University, LHSC-University Hospital, Room B10-007, 339 Windermere Road, London, Ontario, Canada N6A 5A5. Email: joseph.megyesi@lhsc.on.ca

\section{REFERENCES}

1. Brown TJ, Brennan MC, Li M, Church EW, Brandmeir NJ, Rakszawski KL, Patel AS, Rizk EB, Suki D, Sawaya R, Glantz M. Association of the extent of resection with survival in glioblastoma: a systematic review and meta-analysis. JAMA Oncol 2016;2:1460-69.

2. Thomas NWD, Sinclair J. Image-Guided neurosurgery: history and current clinical applications. J Med Imaging Radiat Sci 2015;46: 331-42.

3. Lau JC, Kosteniuk SE, Macdonald DR, Megyesi JF. Image-Guided Ommaya reservoir insertion for intraventricular chemotherapy: a retrospective series. Act Neurochirurgica 2018;160:539-44.

4. Nesvick CL, Khan NR, Mehta GU, Klimo Jr P. Image guidance in ventricular cerebrospinal fluid shunt catheter placement: a systemic review and meta-analysis. Neurosurgery 2015;77: 321-31.

5. Stummer W, Stocker S, Wagner S, Stepp H, Fritsch C, Goetz C, Goetz AE, Kiefmann R, Reulen HJ. Intraoperative detection of malignant gliomas by 5 -aminolevulinic acid-induced porphyrin fluorescence. Neurosurgery 1998;42:518-26.

6. Stummer W, Novotny A, Stepp H, Goetz C, Bise K, Reulen HJ. Fluorescence-Guided resection of glioblastoma multiforme by using 5 -aminolevulinic acid-induced porphyrins: a prospective study in 52 consecutive patients. J Neurosurg 2000;93: 1003-13.

7. Stummer W, Pichlmeier U, Meinel T, Wiestler OD, Zanella F, Reulen HJ, for the ALA-Glioma study group. Fluorescenceguided surgery with 5-aminolevulinic acid for resection of malignant glioma: a randomized controlled multicentre phase III trial. Lancet Oncol 2006; 7:392-401.

8. Hadjipanaysis CG, Stummer W. 5-ALA and FDA approval for glioma surgery. J Neurooncol 2019; 141(3):479-86.

9. Stummer W, Reulen HJ, Meinel T, Pichlmeier U, Schumacher W, Tonn JC, Rohde V, Oppel F, Turowski B, Woiciechowsky C, Franz K, Pietsch T, for the ALA-Glioma Study Group. Extent of resection and survival in glioblastoma multiforme: identification of and adjustment for bias. Neurosurgery 2008; 62: 564-76.

10. Gessler F, Forster MT, Duetzmann S, Mittelbronn M, Hattingen E, Franz K, Seifert V, Senft C. Combination of intraopertative magnetic resonance imaging and intraoperative fluorescence to enhance the resection of contrast enhancing gliomas. Neurosurgery 2015; 77:16-22.

11. Zhao S, Wu J, Wang C, Liu H, Dong X, Shi C, Shi C, Liu Y, Teng L, Han D, Chen X, Yang G, Wang L, Shen C, Li H. Intraoperative fluorescence-guided resection of high-grade malignant gliomas using 5-aminolevulinic acid-induced porphyrins: a systematic review and meta-analysis of prospective studies. PLoS One 2013;8:e63682.

12. Jenkinson MD, Barone DG, Bryant A, Vale L, Bulbeck H, Lawrie TA, Hart MG, Watts C. Intraoperative imaging technology to maximise extent of resection for glioma. Cochrane Database of Systematic Reviews 2018;Issue 1:Art. No.: CD012788.

13. Golub D, Hyde J, Dogra S, Nicholson J, Kirkwood KA, Gohel P, Loftus S, Schwartz TH. Intraoperative MRI versus 5-ALA in high-grade glioma resection: a network meta-analysis. J Neurosurg 2020. DOI: 10.3171/2019.12.JNS191203.

14. Warsi N, Zewude R, Karmur B, Pirouzmand N, Hachem L, Mansouri A. The cost-effectiveness of 5-ALA in high grade glioma surgery: a quality-based systematic review. Can J Neuol Sci 2020. DOI: $10.1017 / \operatorname{cjn} .2020 .78$.

15. Ontario Health (Quality). 5-aminolevulinic acid hydrochloride (5-ALA)-guided surgical resection of high-grade gliomas: a health technology assessment. Ont Health Technol Assess Ser 2020;20(9):1-92. 